\title{
Perancangan Sistem Informasi Manajemen Surat (SIMURAT) Pada AKAKOM Stephen Jambi
}

\author{
$\underline{\text { Ahmad Husaein }}$ \\ Manajemen Informatika, Akademi Akuntansi dan Komputer Stephen Jambi \\ Jl. Halim Perdana Kusuma No. 7 B-C, Kota Jambi, Indonesia \\ hu543in@gmail.com
}

\begin{abstract}
Every organization has a desire to grow. Organizations that want to grow must have a work system with a variety of activities that work together from one part to another to achieve a defined goal. Many organizations do not pay attention to the existence of archives for incoming and outward letter which, if not managed properly, can interfere with the organization's activities. Management of incoming and outgoing mail at AKAKOM Stephen Jambi is done conventionally, causing scattered archives, damaged or even lost. The use of information technology can solve the problem of mail management, so that the archiving of incoming and outward letter and disposition of letters can run quickly, precisely and accurately. The development of a letter management information system (SIMURAT) uses the waterfall method where the process is carried out sequentially or linearly according to the stages in the method. This research produces web-based software that can solve problems in the management of incoming and outward letter.
\end{abstract}

Keyword : Information systems, Management Information systems, letter management, incoming letter, outward letter, letter disposition.

\begin{abstract}
Abstrak
Setiap organisasi memiliki keinginan untuk bertumbuh. Organisasi yang ingin bertumbuh harus memiliki sistem kerja dengan beragam aktifitas yang saling bekerja sama antara bagian yang satu dengan bagian lainnya untuk mencapai suatu tujuan yang ditetapkan. Banyak organisasi yang kurang memperhatikan keberadaan arsip surat masuk dan surat keluar yang jika tidak dikelola dengan baik dapat mengganggu kegiatan organisasi tersebut. Pengelolaan surat masuk dan surat keluar pada AKAKOM Stephen Jambi dilakukan secara konvensional sehingga menyebabkan arsip tercecer, rusak bahkan hilang. Pemanfaatan teknologi informasi dapat mengatasi masalah manajemen surat, sehingga pengarsipan surat masuk dan keluar serta disposisi surat dapat berjalan dengan cepat, tepat dan akurat. Pengembangan sistem informasi manajemen surat (SIMURAT) ini menggunakan metode waterfall dimana proses dilakukan secara berurutan atau secara linier sesuai tahapan dalam metode tersebut. Penelitian ini menghasilkan perangkat lunak berbasis web yang dapat mengatasi permasalahan dalam manajemen surat masuk dan surat keluar.
\end{abstract}

Kata kunci : sistem informasi, sistem informasi manajemen, manajemen surat, surat masuk, surat keluar, disposisi surat.

\section{Pendahuluan}

Suatu lembaga / organisasi secara umum memiliki tujuan ingin berkembang, agar organisasi bisa berkembang maka sistem kerja yang dimiliki harus saling bekerja sama antara unit satu dengan yang lainnya untuk mencapai sasaran yang ditetapkan. Lembaga / organisasi baik pemerintah maupun swasta pada umumnya mempunyai suatu bagian yang bertugas menangani masalah administrasi, dimana pengelolaah kegiatan yang berhubungan kegiatan administrasi tentunya erat kaitannya dengan kegiatan kearsipan [1].

Kearsipan adalah kumpulan warkat yang disimpan secara teratur, terencana, agar apabila suatu saat dubutuhkan dapat ditemukan kembali dengan cepat. Jadi sebagai intinya kearsipan merupakan himpunan lembaran-lembaran tulisan. Catatan tertulis yang disebut warkat harus mempunyai 3 (tiga) syarat yaitu mempunyai sesuatu kegunaan, dapat dengan mudah ditemukan dan disimpan secara berencana dan teratur [2]. Salah satu arsip yang ada organisasi adalah surat. 
Surat adalah salah satu alat komunikasi secara tertulis berasal dari satu pihak yang ditujukan kepada pihak lain untuk menyampaikan berita atau informasi [3]. Surat pada dasarnya adalah alat komunikasi jarak jauh antara manusia dengan mempergunakan bahasa tulisan dan secara kertas sebagai dasarnya. Surat masuk merupakan sarana komunikasi tertulis yang diterima dari instansi lain atau dari perorangan [4]. Setiap surat keluar dan surat masuk yang diterima mempunyai nilai sangat penting, baik sebagai alat komunikasi, sebagai barang bukti otentik dan sekaligus dapat menunjukkan dinamika atau kegiatan pada suatu organisasi [5]. Dokumen organisasi yang dianggap perlu harus diarsipkan dengan baik.

Banyak organisasi yang kurang memperhatikan surat masuk ataupun surat keluar. Surat masuk yang tidak dikelola dengan baik maka akan mengganggu proses kegiatan organisasi atau lembaga.Masalah penanganan surat merupakan masalah utama didalam menjaga keutuhan informasi yang pada suatu saat akan dibutuhkan oleh suatu perusahaan atau organisasi. Penanganan surat harus dilakukan dengan benar serta praktis dan efisien sehingga surat masuk dapat disusun dengan rapi sehingga mempermudah pencarian kembali surat masuk tersebut [6]. Oleh karena itu diperlukan sistem informasi untuk menangani persoalan tersebut.

Perkembangan ilmu pengetahuan dan teknologi menuntut kita berfikit dengan cepat, tepat dan cermat. Banyak kalangan memanfaatkan teknologi sistem informasi pengolahan data sebagai alternatif pemecahan masalah [2]. Dengan memanfaatkan teknologi memungkinkan penyimpanan berbagai arsip surat dapat dilakukan dengan mudah dan akurat [7]. Penyimpanan arsip tersebut dapat berupa file yang memungkinkan memberikan kemudahan dan kenyamanan pada saat melakukan pencarian dan tidak rusak walau pun dimakan waktu [8]. Penyimpanan arsip surat masuk dan surat keluar dengan memanfaatkan teknologi dimungkinkan bisa dikelola dengan mudah, akurat dan tahan lama karena surat disimpan secara elektronik. Hal ini dapat mengurangi penggunaan kertas dan membuat sebagian besar organisasi menggunakan komunikasi berbasis elektronik baik komunikasi dengan unit internal maupun dengan pihak lain. [9]

AKAKOM Stephen Jambi telah memiliki unit yang bertugas menangani arsip surat masuk dan surat keluar, akan tetapi masih belum dikelola dengan baik atau dengan cara konvensional sehingga surat yang tidak dikelola dengan baik akan tercecer, rusak bahkan hilang. Pengagendaan surat yang secara konvensional akan menyulitkan pada saat melakukan pencarian surat, kita harus melihat setiap halaman pada buku agenda dan juga seringkali tulisan yang sulit terbaca karena sudah tersimpan sangat lama dan kemungkinan buku agenda hilang akan mempersulit dalam memperoleh informasi [10]. Oleh karena itu dipandang perlu untuk mengembangkan sebuah sistem yang menangani surat masuk dan surat keluar. Sistem penanganan surat masuk dan keluar diharapkan dapat membantu pihak AKAKOM Stephen Jambi dalam mengelola arsip surat masuk dan keluar. Sistem yang dikembangkan diberikan nama Sistem Informasi Manajemen Surat (SIMURAT).

\section{Metodologi}

Pada tahapan pengembangan sistem ini penulis melakukan tahap demi tahap secara berurutan mulai dari Pengumpulan Data, Analisa Sistem, Design Sistem, Implementasi Sistem, dan Pemeliharaan Sistem. Adapun langkah-langkah yang dilakukan sebagai berikut :

1. Survei Sistem (Pengumpulan Data)

Pengumpulan data dilakukan agar dapat mengetahui sistem yang akan dikembangkan dan data-data yang diperlukan adalah data yang akurat. Untuk memperoleh data yang benar-benar akurat maka dilakukan beberapa proses pengumpulan data yaitu

a. Pengamatan

Selama riset penulis mengamati secara langsung kegiatan-kegiatan pada AKAKOM Stephen Jambi, yang berkaitan dengan pengarsipan surat masuk, surat keluar dan disposisi surat pada unit yang bertanggung jawab terhadap tugas ini.

b. Wawancara

Wawancara dilakukan dengan memberikan pertanyaan langsung kepada Wakil Direktur Bidang Akademik, Front Office, Kepala BAU, Kepala BAAK terkait dengan proses atau SOP proses pengarsipan surat, surat masuk, surat keluar dan disposisi surat. 
c. Studi Pustaka

Pada tahapan penulis mendapatkan sumber referensi dari buku, makalah jurnal atau referensi lainnya yang berkaitan dengan pengembangan sistem informasi pengarsipan surat masuk dan surat keluar.

2. Analisa Sistem

Pada tahap ini dilakukan identifikasi kebutuhan dari sistem yang akan dikembangkan. Berdasarkan data yang diperoleh pada tahapan 1, selanjutnya dilakukan analisa kebutuhan sistem yang akan dikembangkan, tahapan proses penerimaan surat masuk, proses surat keluar dan melakukan disposisi surat. Proses analisa sistem ini nantinya akan memberikan gambaran jelas untuk tahapan berikutnya.

3. Desain Sistem

Pada tahapan dilakukan proses desain sistem diantaranya use case diagram, activity diagram, class diagram, berdasarkan proses analisa yang dilakukan pada tahapan ke 2. Selanjutnya pada tahapan dini juga digambarkan rancangan input, dan rancangan output dari sistem informasi manajemen surat..

4. Implementasi

Pada tahap ini dilakukan pembuatan aplikasi atau sistem berbasis komputer yang akan dikembangkan berdasarkan rancangan pada tahap sebelumnya dengan menggunakan bahasa pemrograman PHP framework (Codeigniter) dengan MySQL sebagai database. Setelah sistem dikembangkan selanjutnya dilakukan pengujian terhadap modul yang dihasilkan dengan harapan dapat diketahui apakah sistem yang dikembangkan telah sesuai dengan kebutuhan tanpa adanya kesalahan.

5. Maintenance / Perawatan

Pada tahap ini dilakukan proses maintenence / perawatan sistem yang telah dikembangkan. Maintenence / perawatan yang dimaksud yaitu memperbaiki kesalahan yang tidak ditemukan pada tahap sebelumnya serta penambahan modul baru sesuai dengan kebutuhan.

Tahapan demi tahapan digunakan sebagai acuan dalam proses pengembangan sistem secara keseluruhan. Tahapan yang dilakukan memberikan gambaran bagaimana proses pengembangan sistem secara keseluruhan mulai dari pengumpulan data, analisa, desain sistem, implementasi dan perawatan. Penerapan metode waterfall dilakukan sampai dengan proses penyelesaian akhir perangkat lunak dan proses pengujian untuk membuktikan bahwa sistem yang telah dikembangkan layak untuk digunakan.

\section{Hasil dan Pembahasan}

Berdasarkan hasil pengumpulan data yang peroleh dan analisa sistem yang dilakukan terhadap kebutuhan dari pengembangan sistem informasi antara lain adalah membantu dalam pengelolaan dan pengarsipan surat menyurat, mulai penerimaan / pengarsipan surat, mendisposisikan surat, secara keseluruhan dapat dilakukan secara on-line. Secara detail, kemampuan dari Sistem Informasi Manajemen Surat dapat dilihat dari use case diagram seperti pada gambar 1. Use Case diagram digunakan untuk menggambarkan sistem berdasarkan sudut pandang dari pengguna sistem tersebut (user), sehingga diagram use case diagram dibuat lebih menitik beratkan pada fungsionalitas[11].

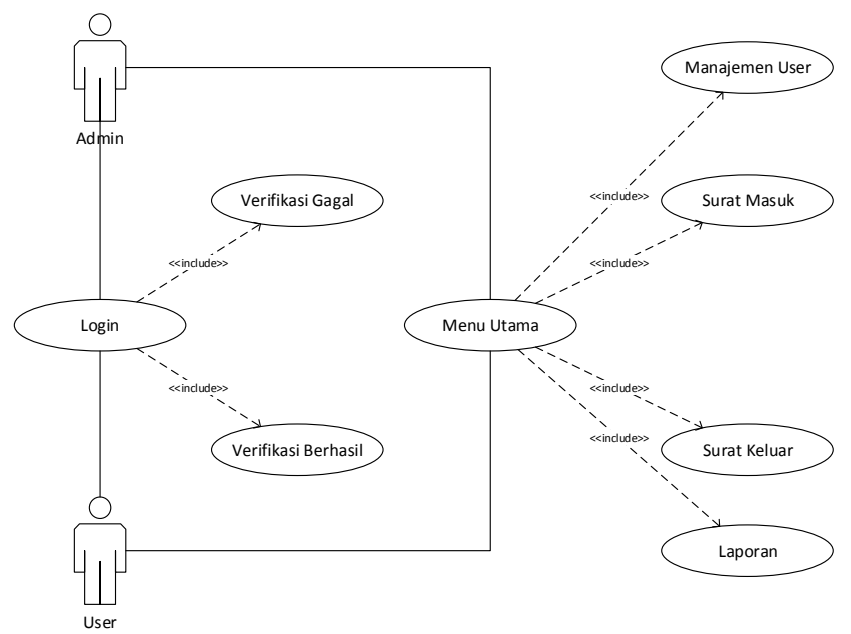

Gambar 1, Use Case Diagram Sistem Informasi Manajemen Surat 
Pada gambar 1, Diagram Use Case ini memiliki 2 aktor yaitu admin dan user, untuk dapat mengakses fasilitas aktor harus melakukan login terlebih dahulu, selajutnya login akan melakukan verifikasi berhasil atau gagal, apabila proses verifikasi berhasil maka aktor dapat mengakses menu utama. Selanjutnya aktifitas yang terjadi didalam sistem digambarkan pada diagram aktifitas.

Activity diagram merupakan bentuk khusus dari state machine yang memodelkan komputasi-komputasi serta aliran kerja pada sebuah sistem atau perangkat lunak yang dikembangkan [12]. Aktifitas utama dalam sistem ini, yaitu aktifitas Penerimaan Surat (Surat Masuk), Disposisi, dan Surat Keluar, aktifitas ini dijelaskan dalam Activity Diagram seperti pada gambar 2.

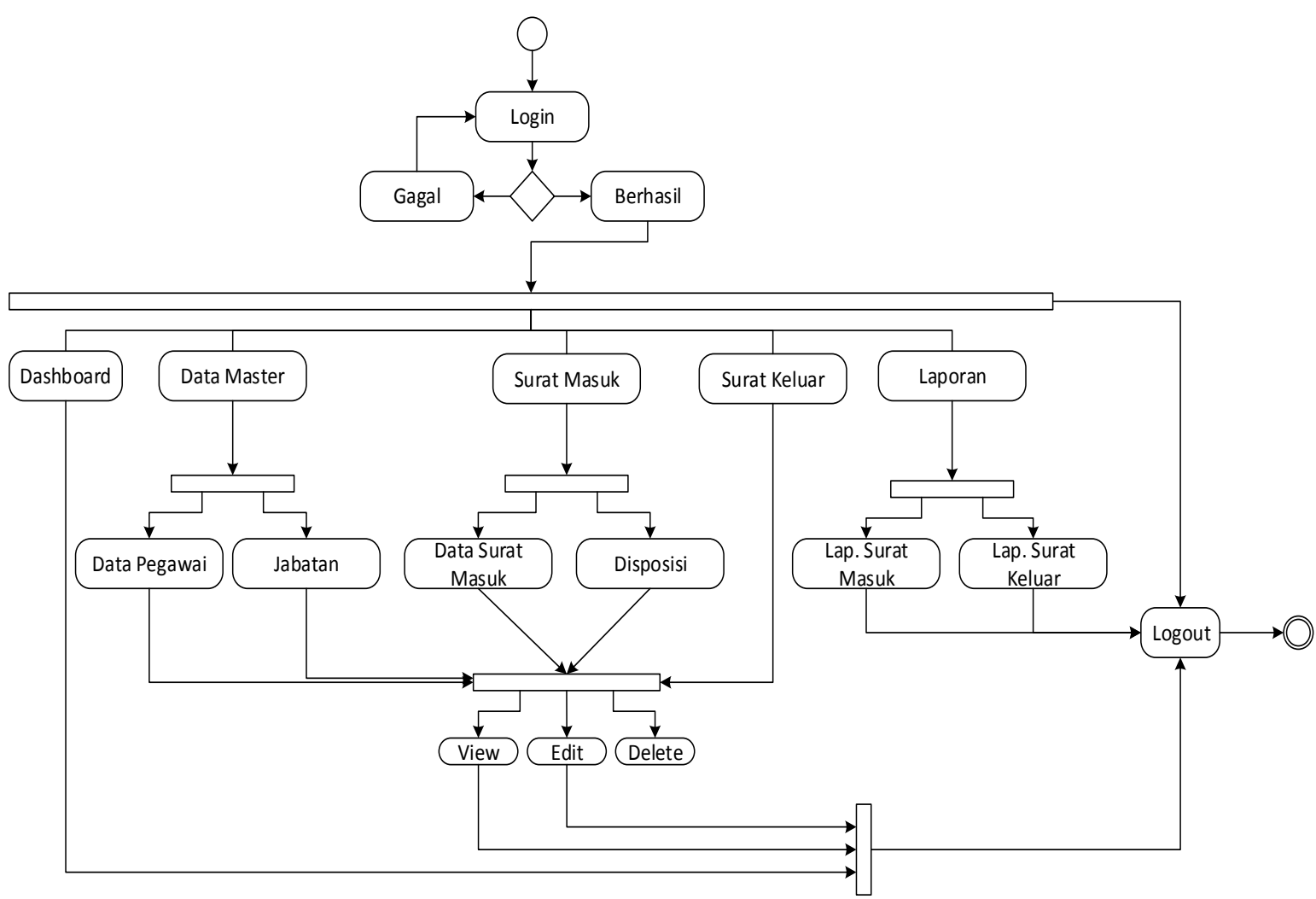

Gambar 2, Activity Diagram Sistem Informasi Manajemen Surat

Pada diagram diatas diawali dengan melakukan proses login dilanjutkan dengan verifikasi apabila login gagal maka akan kembali ke halaman login, apabila login berhasil maka akan masuk ke halaman menu utama. Pada halaman utama terdapat beberapa pilihan diantaranya dashboard, data master surat masuk, surat keluar dan laporan. Pada surat masuk user dapat melakukan pendataan surat masuk, disposisi surat. Untuk mengakhiri proses dari sistem user harus melakukan logout.

Berdasarkan hasil analisis dan desain sistem diatas perlu dilakukan inplementasi dari hasil rancangan menjadi antar muka (Interface) pada pemrograman berbasis web. Implementasi antar muka terdiri dari :

1. Halaman Login

Tampilan ini berfungsi untuk memeriksa apakah user atau pengguna memiliki hak akses dengan cara memasukkan nama user dan password selanjutnya mengklik tombol login. Jika berhasil maka akan tampil menu utama / dashboard, jika tidak maka akan ada pesan bahwa username dan password salah atau user tidak terdaftar maka user tidak dapat menggunakan aplikasi ini. Tampilan menu login dapat dilihat pada gambar 3. 


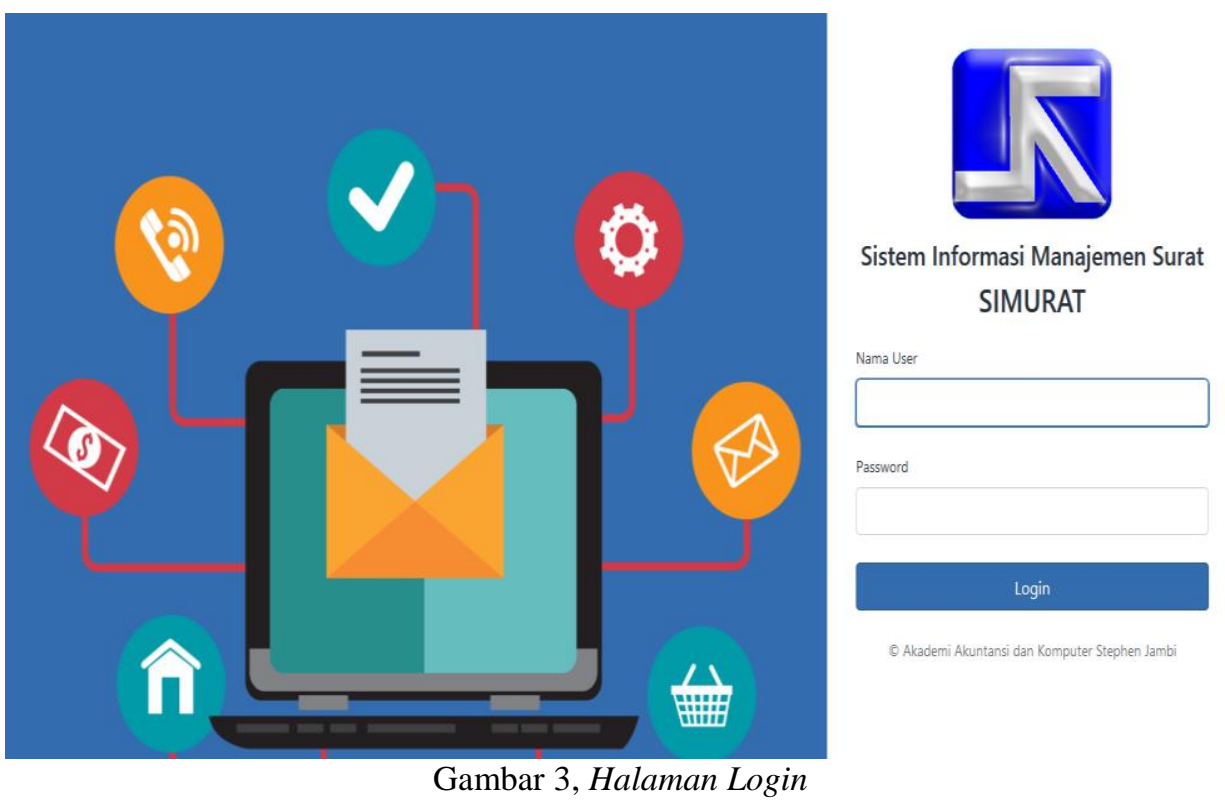

2. Tampilan Menu Utama / Dashboard

Tampilan ini berisi menu utama yang terdiri dari tabel referensi, surat masuk, surat keluar dan disposisi. Tabel referensi memiliki sub menu diantaranya struktur jabatan, jenis surat dan instruksi disposisi. Tampilan menu utama seperti pada gambar 4
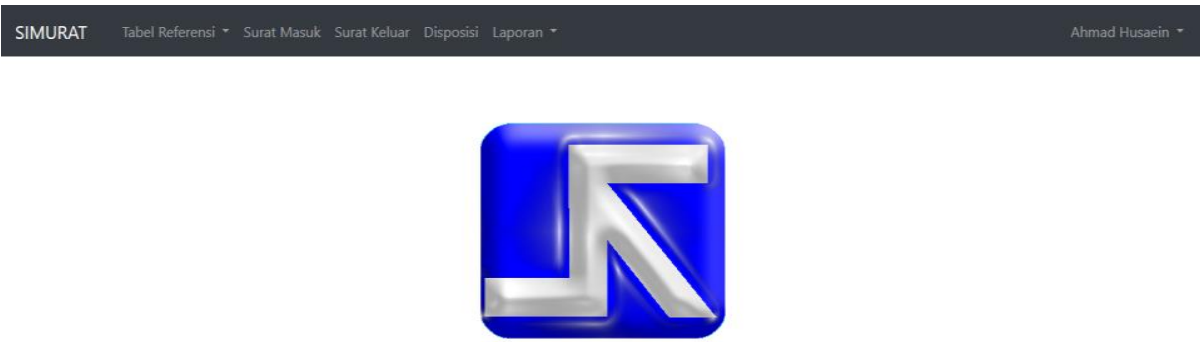

SIMURAT

Sistem Informasi Manajemen Surat AKAKOM STEPHEN JAMB

\section{Gambar 4. Halaman Dashboard}

3. Tampilan Form Surat Masuk \& Disposisi

Form ini berfungsi untuk mendata dan mengarsipkan surat masuk, disamping itu tampilan ini juga memberikan informasi arsip masuk pada AKAKOM Stephen Jambi. Tampilan form surat masuk seperti pada gambar 5 . 


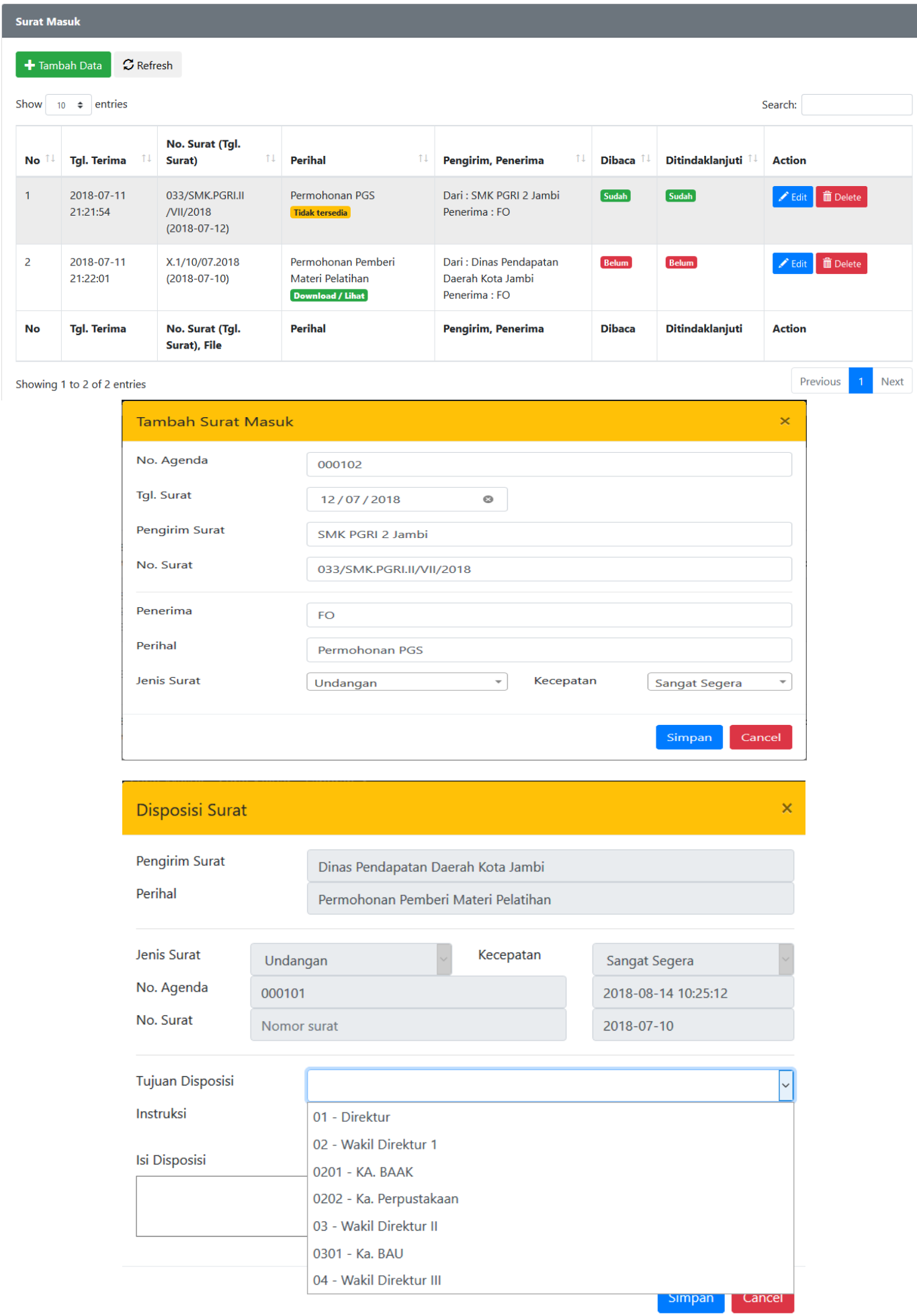

Gambar 5. Halaman Surat Masuk dan Disposisi

4. Tampilan Form Surat Keluar

Form ini berfungsi untuk mendata dan mengarsipkan surat keluar, disamping itu tampilan ini juga memberikan informasi arsip keluar pada AKAKOM Stephen Jambi. Tampilan form surat keluar seperti pada gambar 6 . 


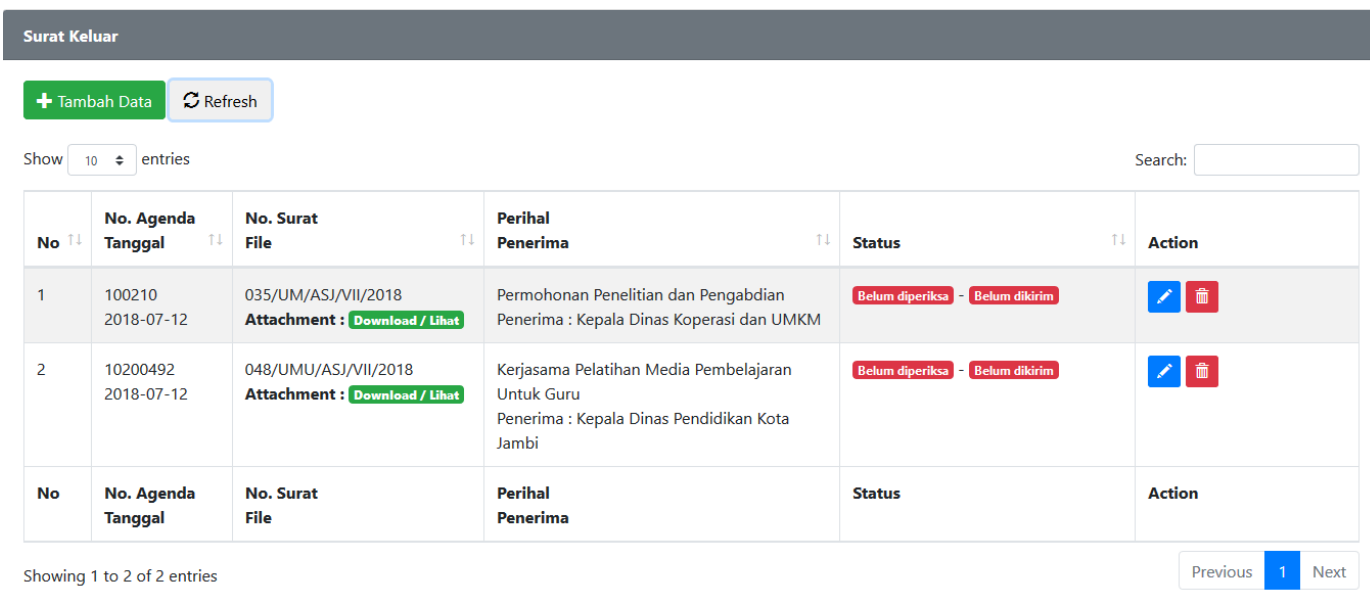

Gambar 6. Halaman Surat Keluar

Pengujian yang digunakan untuk menguji aplikasi SIMURAT meliputi surat masuk, disposisi dan surat keluar. Dalam pengujian sistem ini digunakan metode pengujian black box. Pengujian black box dilakukan dan berfokus pada persyaratan fungsional perangkat lunak. Pengujian black box merupakan pengujian fungsional pada tahapan pembangun sistem. Pengujian Sistem dilakukan terhadap hasil perancangan Sistem dibangun. Hasil dari pengujian yang dilakukan dapat dilihat pada tabel 1.

Table 1. Pengujian Sistem

\begin{tabular}{|c|c|c|c|c|c|}
\hline No & $\begin{array}{c}\text { Antar } \\
\text { muka } \\
\text { yang diuji }\end{array}$ & $\begin{array}{c}\text { Bagian } \\
\begin{array}{c}\text { Antarmuka yang } \\
\text { diuji }\end{array} \\
\end{array}$ & $\begin{array}{l}\text { Prosedur } \\
\text { Pengujian }\end{array}$ & $\begin{array}{c}\text { Hasil yang } \\
\text { diharapakan }\end{array}$ & $\begin{array}{c}\text { Hasil yang } \\
\text { didapat }\end{array}$ \\
\hline 1 & Login & $\begin{array}{lr}\text { Tampilan } & \text { login, } \\
\text { Textbox } & \text { dan } \\
\text { tombol } & \end{array}$ & $\begin{array}{l}\text { Buka aplikasi, isi } \\
\text { Textbox, tekan } \\
\text { tombol login }\end{array}$ & $\begin{array}{l}\text { Menampilkan Form } \\
\text { login, Textbox dapat di } \\
\text { isi, tombol login dapat di } \\
\text { klik, menampilkan Form } \\
\text { menu utama }\end{array}$ & Tercapai \\
\hline 2 & $\begin{array}{l}\text { Mengarsip } \\
\text { surat }\end{array}$ & $\begin{array}{l}\text { Textbox, tombol } \\
\text { scan, } \\
\text { simpan, tombol } \\
\text { pencarian data }\end{array}$ & $\begin{array}{l}\text { Pilih menu surat } \\
\text { masuk atau } \\
\text { keluar, isi data } \\
\text { berdasarkan data } \\
\text { surat, simpan } \\
\text { kedalam database }\end{array}$ & $\begin{array}{l}\text { Menampilkan Form arsip } \\
\text { surat, Textbox dapat diisi, } \\
\text { tombol scan berfungsi } \\
\text { tombol simpan dapat } \\
\text { menyimpan data arsip } \\
\text { surat }\end{array}$ & Tercapai \\
\hline 3 & Disposisi & $\begin{array}{l}\text { Textbox, tombol } \\
\text { disposisi, } \\
\text { menampilkan data } \\
\text { pencarian, } \\
\text { menampilkan } \\
\text { lembar hasil scan } \\
\text { surat }\end{array}$ & $\begin{array}{l}\text { Pilih menu pilih } \\
\text { disposisi. Pilih } \\
\text { surat masuk yang } \\
\text { akan di disposisi } \\
\text { isi data disposisi } \\
\text { surat, tekan } \\
\text { tombol kirim }\end{array}$ & $\begin{array}{lr}\text { Menampilkan } & \text { Form } \\
\text { disposisi. } & \text { Dapat } \\
\text { menyimpan data dan } \\
\text { menampilkan data yang } \\
\text { tersimpan }\end{array}$ & Tercapai \\
\hline 4 & $\begin{array}{l}\text { Cetak } \\
\text { laporan } \\
\text { surat } \\
\text { masuk }\end{array}$ & $\begin{array}{l}\text { Pencarian } \\
\text { berdasarkan filter } \\
\text { tanggal, tombol }\end{array}$ & $\begin{array}{l}\text { Pada menu utama } \\
\text { pilih laporan surat } \\
\text { masuk, tentukan } \\
\text { tanggal yang } \\
\text { ingin di cetak } \\
\text { pilih print untuk } \\
\text { mencetak }\end{array}$ & $\begin{array}{l}\text { Menampilkan Form } \\
\text { filter, menampilkan hasil } \\
\text { filter surat dalam bentuk } \\
\text { PDF dan microsoft excel }\end{array}$ & Tercapai \\
\hline 5 & $\begin{array}{l}\text { Cetak } \\
\text { laporan } \\
\text { surat } \\
\text { keluar }\end{array}$ & $\begin{array}{l}\text { Pencarian } \\
\text { berdasarkan filter } \\
\text { tanggal, tombol }\end{array}$ & $\begin{array}{l}\text { Pada menu utama } \\
\text { pilih laporan surat } \\
\text { keluar, tentukan } \\
\text { tanggal yang } \\
\text { ingin di cetak }\end{array}$ & $\begin{array}{l}\text { Menampilkan Form } \\
\text { filter, menampilkan hasil } \\
\text { filter surat dalam bentuk } \\
\text { PDF dan microsoft excel }\end{array}$ & Tercapai \\
\hline
\end{tabular}




\section{Kesimpulan}

Dengan dikembangkannya sebuah sistem informasi manajemen surat, diharapkan dapat meningkatkan pelayanan dan arsip surat menyurat antar unit kerja didalam organisasi maupun diluar organisasi, melalui aplikasi ini dapat mengurangi penggunaan kertas pada saat melakukan dispoisis surat, dan arsip disimpan secara elektronik.Untuk penelitian kedepan disposisi surat dapat diterima melalui aplikasi mobile dengan memberikan notifikasi pesan, sehingga surat masuk dapat diterima dan diakses kapanpun dan dimanapun.

\section{Daftar Rujukan}

[1] R. Maulana Syaban and H. Bunyamin, "Pengembangan Sistem Informasi Pengelolaan Surat Masuk dan Surat Keluar Berbasis Web di Dinas Sosial Tenaga Kerja dan Transmigrasi Kabupaten Garut Menggunakan Framework PHP," Jurnal Algoritma, vol. 12, no. 2, pp. 301-311, 2016.

[2] D. Haryanto and A. Nasihin, "Sistem Informasi Kearsipan Surat Masuk Surat Keluar di STIKes Mitra Kencana Kota Tasikmalaya,” Jurnal teknik informatika, vol. 6, no. 2, pp. 22-30, 2018.

[3] H. T. Sitohang, "Sistem Informasi Pengagendaan Surat Berbasis Web Pada Pengadilan Tinggi Medan," vol. 3, no. 1, pp. 6-9, 2018.

[4] A. E. Sawitri and A. Irhandayaningsih, "Analisis Penggunaan Aplikasi Tata Surat Dalam Pengelolaan Surat Masuk Dan Surat Keluar Pada Dinas Kesehatan Provinsi Jawa Tengah,” Jurnal Ilmu Perpustakaan, vol. 6, no. 3, pp. 411-420, 2019.

[5] D. P. Dewi and L. Octavia, "Peran Sekretaris Dalam Mengelola Surat Masuk Dan Surat Keluar Pada Dinas Perpustakaan Dan Arsip Daerah Kota Tangerang Selatan,” Sekretari, vol. 4, no. 2, p. 20, 2018.

[6] J. Prawono and A. Pamungkas, "Sistem Informasi Pengelolaan Surat Masuk Dan Surat Keluar Di STMIK AUB Surakarta," Informatika, vol. 2, no. 1, p. $242651,2015$.

[7] A. Suryadi, "Rancang Bangun Sistem Pengelolaan Arsip Surat Berbasis Web Menggunakan Metode Waterfall (Studi Kasus : Kantor Desa Karangrau Banyumas)," Jurnal Khatulistiwa Informatika, vol. 7, no. 1, pp. 13-21, 2019.

[8] F. Masykur, I. Makruf, and P. Atmaja, "Sistem Administrasi Pengelolaan Arsip Surat Masuk Dan Surat Keluar Berbasis Web,” vol. 4, no. 3, pp. 1-7, 2015.

[9] R. A. P. Wade, "ISSN : 2355-9365 e-Proceeding of Engineering : Vol.2, No.3 Desember 2015 | Page 7666 Pengembangan Aplikasi E-Office Pencatatan Dokumen Pada Badan Kepegawaian Daerah Propinsi Jawa Bbarat Dengan Menggunakan Metode RAD Application," in e-Proceeding of Engineering, 2015, vol. 2, no. 3, pp. 7666-7673.

[10] A. T. D. Santosa, "Sistem Informasi Administrasi Surat Masuk Dan Surat Keluar Pada Badan Kepegawaian Daerah Kota Semarang," Universitas Dian Nuswantoro Semarang, p. 3, 2015.

[11] M. Hatta, M. M. Anwar, I. N. Diana, and M. H. Amarul M, "Perancangan Sistem Informasi Pengarsipan Dan Disposisi Surat Berbasis Web Dengan Menggunakan Framework Codeigniter," SCAN - Jurnal Teknologi Informasi dan Komunikasi, vol. 14, no. 2, 2019.

[12] A. Nugroho, Rekayasa Perangkat Lunak Berorientasi Objek dengan Metode USDP. Yogyakarta: Andi Offset, 2010. 